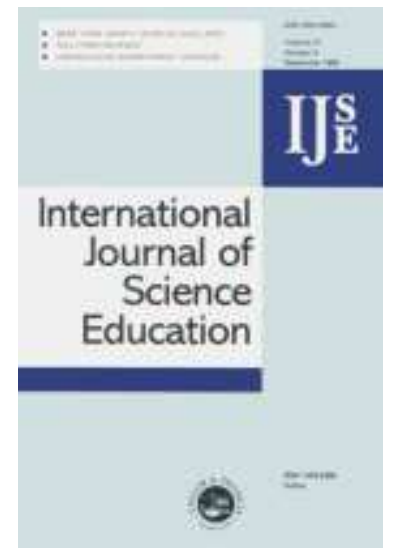

\title{
Primary Teachers' Particle Ideas and Explanations of Physical Phenomena: The Effect of an In-Service Training Course
}

\begin{tabular}{|r|l|}
\hline Journal: & International Journal of Science Education \\
\hline Manuscript ID: & TSED-2008-0228.R2 \\
\hline Manuscript Type: & Research Paper \\
\hline Keywords: & $\begin{array}{l}\text { teacher knowledge, science education, in-service, primary school, } \\
\text { misconception }\end{array}$ \\
\hline Keywords (user): & Particle ideas, Physical phenomena \\
\hline
\end{tabular}

\section{S) ScholaroNE \\ Manuscript Central}




\title{
Running head: Primary Teachers' Ideas of Physical Phenomena
}

\section{Primary Teachers' Particle Ideas and Explanations of Physical}

\section{Phenomena: The Effect of an In-Service Training Course}

\begin{abstract}
This paper presents a study concerning Greek primary school teachers' $(n=162)$ ideas about the particulate nature of matter and their explanations of physical phenomena. The study took place during an in-service training course where the effectiveness of a specially designed intervention was tested. A key feature was an approach based on the concept of a substance and its states rather than 'solids, liquids and gases'. Pre-intervention, the teachers held misconceptions similar to those of pupils. Also, there seemed to be some relationship between the teachers' particle model ideas and their explanations of phenomena. Postintervention, the teachers' descriptions and explanations were found to be significantly improved, with almost zero correlation between pre and post intervention scores. Implications for science education are discussed.
\end{abstract}

\section{Keywords \\ Primary teachers, Particle ideas, Physical phenomena, In-service training}

\section{Introduction}

The late 1980s saw a shift from a largely process approach to a greater emphasis on subject knowledge for primary school science in the USA, UK, Australia and New Zealand (Osborne \& Simon, 1996). At that time, the Greek primary science curriculum was reconstructed to also feature content more prominently (Greek Ministry of National Education and Religion Affair, 1985). These curricular changes placed demands on in-service primary teachers for which few were well qualified, particularly in the physical sciences. Indeed, 
Running head: Primary Teachers' Ideas of Physical Phenomena

research revealed that many primary teachers were low in their confidence to teach science and held similar misconceptions to pupils (Appleton, 1995; Baker, 1994; Harlen, Holroyd \& Byrne, 1995; Krugar, Summers \& Palacio, 1990; Mant \& Summers 1995; Smith \& Neal, 1989; Summers, 1992; Summers \& Krugar, 1992). It is difficult to see how lack of subject knowledge would not impact on the quality of teaching. Without sound understanding of the content, how could a teacher plan appropriate, imaginative lessons and engage in constructive dialogue with pupils? Instead, there is the danger of the teacher being a source of misconceptions and confusion. A robust subject content knowledge would seem to be a necessary support for pedagogical content knowledge which develops pupils' conceptual learning (Kang, 2007). Moreover, poor science teaching is likely to generate negative attitudes towards science in pupils (Harlen \& Holroyd, 1997; Jurievi, Glaar, Puko \& Devetak, 2008; Woolnough, 1994).

More recent studies indicate that the problem appears to persist despite greater attention to science within pre-service and in-service courses for two decades (Appleton, 2002, 2003; Author \#1 et al., 2000, 2007; Jarvis, Pell \& Mckeon, 2003; Murphy, Neil \& Beggs, 2007; Parker \& Heywood, 2000; Schibeci \& Hickey, 2000). There is a continuing need for in-service provision. Studies reporting interventions, both pre-service and in-service, are commonly structured upon a constructivist teaching methodology (e.g. Çalik, 2008; Jarvis \& Pel, 2004; Liang \& Gabel, 2005; Schibeci \& Hickey, 2000; Summers, 1992). The extent to which such interventions also involve important changes in content (the ideas being taught) is not always clear. In this paper we report a study where the emphasis was on a rethinking of the content.

The nature of matter and its transformations is perhaps an especially problematic domain area because of the issues surrounding the particulate model of matter. The area has been widely investigated from the pupils' perspective across the primary and secondary age ranges. Findings indicate a large discrepancy between pupils' explanations of physical 


\section{Running head: Primary Teachers' Ideas of Physical Phenomena}

phenomena (melting, boiling, evaporation, condensation and dissolving) and the science view (e.g. Andersson, 1990; Author \#1 \& \#3, 2005; Author \#3, 1998b,c; Bar \& Galili, 1994; Bar \& Travis, 1991; Costu \& Ayas, 2005; Lee, Eichinger, Anderson, Berkheimer \& Blakeslee, 1993; Osborne \& Cosgrove, 1983; Paik, Kim, Cho \& Park, 2004; Russell, Harlen \& Watt, 1989; Stavey, 1990; Tytler, 2000). This work also reveals widespread difficulties with the particulate theory of matter (e.g. see Andersson, 1986; Author \#3, 1998a; Barker, 2002; Driver, Squires, Rushworth \& Wood-Robinson, 1994; Gabel \& Bunce, 1994; Garnett, Garnett \& Hackling, 1995; Gomez, Benarroch \& Marin (2006); Hatzinikita, Koulaidis \& Hatzinikitas, 2005; Krnel, Watson \& Glazar, 1998; Liu, 2001; Smith, Anderson, Krajck \& Coppola, 2004 ). Similar findings are reported in studies with pre-service teachers (e.g. Çalik \& Ayas, 2005; Jarvis, Pell \& Mckeon, 2003; Kokkotas, Vlachos \& Koulaidis, 1998; Schoon \& Boone, 1998; Tekkaya, Cakiroglu \& Ozkan, 2004).

Given the research on pupils' difficulties, there is debate as to when the particle model should be introduced. At present, it is found in the early secondary curriculum in most countries (Martin, Mullis, Gonzales \& Chrostowski, 2004) and there is an argument for postponement (Harrison \& Treagust, 2002). Certainly, in the UK and Greece, it is not part of the official primary curriculum. However, one's position on the introduction of the particle model depends on one's belief in the reasons for pupils' difficulties. We contend that the conceptual accuracy of the particle model on offer, rather than pupils' capabilities (or teachers' pedagogical abilities) is the prevailing limiting factor (Author\#3 \& \#1, 2008). Without first distinguishing between substances and mixtures of substances, the model is usually introduced to explain 'solids', 'liquids' and 'gases'. Differences in melting and boiling points are not addressed. In all, this could be confusing and therefore have little utility. Scientifically, there are no such things as 'solids', 'liquids' and 'gases': there are substances and their states (with mixtures of substances often having complex behaviour). Talk of 'solids', 'liquids' and 'gases' may lead pupils to think that these are three separate kinds of 


\section{Running head: Primary Teachers' Ideas of Physical Phenomena}

matter (Author\#3, 1996) and hence there must be three types of particle which carry the respective macroscopic properties, a common misconception (e.g. Andersson, 1990; Ben-Zvi, Eylon, \& Silberstein,1986; Gabel \& Sumuel 1987; Griffiths \& Preston, 1992; Kokkotas, Vlachos \& Koulaidis, 1998; Pereira \& Pestana, 1991). Changes of state in some instances are then seen as perplexing anomalies. We advocate an approach which focuses on the concept of a substance and its states. Furthermore, we would argue that particulate ideas are necessary to sharing the scientific view of events on a macroscopic scale. For example, without identifying a substance with a kind of particle how can one accept that the substance water can be part of the clear air - be there to separate out on cooling the mixture? (Pupils seem to find the appearance of condensation on a cold object one of the most difficult events to understand.).

If particle theory needs to be an integral part of teaching about physical changes one must ask whether this package is appropriate for the primary curriculum. However, if the standard approach to introducing the particulate view of matter is flawed we cannot say yet what pupils could achieve otherwise at various ages. Using our new conceptual approach, short intervention studies with primary aged pupils have yielded encouraging results (Authors \#1 \& \#3, 2005; Authors \#1, \#3 \& other, 2008; Author\#3 \& \#1, 2008). If primary pupils can engage with particle ideas, their teachers ought to be capable. However whether this can be realised in practice remains an empirical question, too. At older ages, teachers who have held misconceptions throughout their school years and teaching careers may be resistant to change - a widely noted characteristic of 'misconceptions'.

In this paper we report the outcome of an in-service course, which adopted a substance approach to the particle model and physical changes, for Greek primary teachers. In this context the following two research questions were addressed:

- What was the affect of the course on teachers' understanding of the particle model and their explanations of physical phenomena during this course? 


\section{Running head: Primary Teachers' Ideas of Physical Phenomena}

- What is the relationship between the degree of teachers' understanding of the particle model and their explanations of physical phenomena?

In both questions, commonalities with pupils' thinking were also examined.

\section{The content and structure of the training course}

The study took place during an in-service teachers' professional development program. Under central control from the Greek Ministry of National Education and Religion Affairs each Primary Educational Department of Greek Universities had the responsibility for planning and implementing a particular training program. These were open to Greek primary teachers with up to 25 years teaching experience, on a voluntary basis. In this context, Democritus University of Thrace launched a two-year program, where, among other courses, participants attended a five week (six hours per week) training course on basic concepts of chemistry. The conceptual structure and content of the course had been developed by two of the authors (the $1^{\text {st }}$ and the $3^{\text {rd }}$ ).

Table 1 outlines the content covered by the course with respect to physical changes (further work on chemical change is not reported here). Similar content has been used with Greek primary pupils (Authors \#1 \& \#3, 2005; Authors \#1, \#3 \& other, 2008). The rational behind the scheme is discussed in full elsewhere (Author\#3 \& \#1, 2008) and we give just a brief overview here.

\section{[Insert Table 1 about here.]}

Given the expected weaknesses in the teachers' background knowledge, the scheme starts by identifying properties which depend on the material only. Here material means any recognizable kind of 'stuff' be it a substance (element or compound) or a mixture of substances. Next, melting behaviour is used to give an operational definition of a substance: a sample of stuff which has a precise melting point (there is a sharp change between solid and liquid) as opposed to a mixture which melts over a temperature range. The particulate view of 


\section{Running head: Primary Teachers' Ideas of Physical Phenomena}

matter is then introduced to explain why a substance can change between the solid and liquid states. At the outset, the intention is to counter any suggestions that 'solids' and 'liquids' are two types of matter. A simple model is presented which talks about the "particles of a substance', where the identity of the substance rests with the particles: different substances are different particles (there is no distinction between molecules, atoms or ions). These particles have an 'ability to hold' on to each other (which is different for different substances) and an energy of movement (which depends on the temperature). The 'ability to hold' is a characteristic of a substance and does not change on change of state. Melting is explained by increased energy of movement which partially overcomes the hold so the particles can move around from place to place, but are still kept close together. The particles themselves, whatever their physical nature, do not change. Following on, the change to the gas state (boiling) is explained by the particles having enough energy to completely overcome the 'hold'. Crucially, the coexistence of different substances in different states at the same temperature is explained by differences in the 'ability to hold' (which give different melting and boiling points). Substances in the gas state at room temperature have a very weak hold between their particles - they are not a different kind of matter. (NB: We prefer to use 'hold' rather than attraction since 'hold' anticipates later refinement into the idea of a bond as a balance between attraction and repulsion.) Finally, the idea of a distribution of energy amongst particles at a particular temperature is introduced to explain evaporation of water into the air at room temperature, and the separation of water from the air on cooling.

\section{Methodology}

Sample

One hundred and sixty two primary school teachers (68 male and 94 female) participated in the present study. All were working in primary schools in the area of East Macedonia and Thrace, Greece, and their teaching experience ranged from 2 to 21 years 


\section{Running head: Primary Teachers' Ideas of Physical Phenomena}

(mean 12.7 and $\mathrm{SD}=4.5$ ). The teachers had not participated in any similar in-service training programs previously. Their undergraduate studies on general science had been the only formal education on this matter. During their in-service teaching they would have acquired similar experiences, since all would have been using the same mandated textbook and guidance (Greek Pedagogical Institute, 2003). It should be stressed here that teaching experience does not necessarily enhance conceptual learning or bring expertise in science teaching (Morrison \& Lederman, 2003).

\section{Teaching}

The teaching took place in nine independent locations, each with a class of 18 participants. The whole course consisted of 30 one-hour lessons; six covered sections 1 to 3 of Table 1 (the particulate nature of substances) and nine covered sections 4 and 5 (explanations of corresponding physical phenomena). The remaining lessons covered chemical change (not reported here). All of the teaching was carried out by the first author.

Simple demonstration experiments (e.g. melting of wax, melting of chocolate, boiling of water) were used in the lessons. For each of these, 2-3 teachers were invited to participate (handling materials, heating etc.), while the rest observed. Overall, most of the teachers in each class did not volunteer, saying that they didn't feel comfortable with such experiments and preferred to watch. Only around 4-8 teachers in each class had direct involvement in one or more these demonstrations. For more difficult or time-consuming experiments, appropriate videos were used (e.g. evaporation of alcohol or water, boiling of wax). All teachers participated in discussions on the observations and explanations. Static representations concerning the particulate nature of substances were used as aids. 


\section{Running head: Primary Teachers' Ideas of Physical Phenomena}

\section{Measurements and Instruments}

At the beginning of the course the teachers completed a pre-intervention written test consisting of two parts (Table 2). Part I concerns the understanding of the particle model itself and Part II concerns the application of the model to explain phenomena. In sum, Parts I and II relate to the first research question. Setting the two parts against each other addresses the second research question.

Part I contained two groups of tasks - five tasks in total. The groups correspond to two dimensions in which the degree of the development of particle ideas can be measured, namely, the Particulate/ Continuous dimension and the Macroscopic/ Collective dimension. These dimensions had emerged from a longitudinal study on pupils' understanding of the particulate view of matter (Author \#3, 1998a). The former concerns the development of the notion of particles in terms of the relationship between the particles and the substance. At one end a completely continuous view of matter is held, at the other the particles are the substance. Between these two ends, the particles are embedded in the substance with varying degrees of association between the particles and the substance. The macroscopic/collective dimension relates to the association between the particles and the macroscopic properties of a state. At one end all of the macroscopic properties are carried by each individual particle. At the other end, the macroscopic properties are explained by the collective behaviour of the particles (and the physical nature of individual particles is irrelevant).

Part II consisted of four tasks, which concern measurements on the description and explanation of physical phenomena: melting, boiling, evaporation and condensation. Descriptions of all the instrument tasks for Parts I and II are given in Table 2. Figure 1 gives some of the representations used. A month after the training course, the same instrument was used as a post-intervention test. The total time period for the completion of the tests was one hour (60 min) each.

[Insert Table 2 about here] and [Insert Figure 1 about here] 


\section{Running head: Primary Teachers' Ideas of Physical Phenomena}

\section{Data analysis}

As the instrument was a written test applied to a large sample the data analysis is mainly quantitative. Qualitative characteristics of answers were used for categorization, but are not reported and discussed in detail. In each one of the tasks, teachers' answers were categorized according to their correctness by two of the authors (the $1^{\text {st }}$ and the $2^{\text {nd }}$ ). The agreement percentage after discussion and negotiation became $100 \%$. Depending on the task, a teacher's answer could be characterized as: correct (C), partially correct (PC), not entirely incorrect (NEI) and incorrect (I). The corresponding scores awarded for these categories were 3 to 0 , respectively. In some tasks the categorization resulted in three levels: correct, partially correct and incorrect and the scores awarded were 2 to 0 , respectively. Total scores were calculated as sums and were used as percent achievement for further statistical analysis.

The validity of the test concerns the evaluation of achievement in a specific domain and thus it refers to content validity (Mertens, 2005, p 354). Thus, the establishment of this type of validity was based on elaborated judgement and expertise. The Cronbach's alpha was 0.69 and 0.59 for pre and post intervention questionnaires, respectively. Although not very high, they are satisfactory as indicators for internal consistency. Values down to 0.55 are acceptable for statistical consideration in social science studies (Hatcher \& Stepansky, 1994). However, the low Cronbach's $\alpha$ values in this case are not definitely related to lack of internal consistency. Kline (1999) notes that values below 0.7 can be expected in cognitive tests due to the diversity of constructs being measured.

\section{Results and Discussion}

In this section the results of the pre- and post- intervention tests are presented, discussed and compared with previous research findings. Parts I and II are considered separately and then in relation to each other through statistical analysis. 


\section{Running head: Primary Teachers' Ideas of Physical Phenomena}

\section{Part I. Structure of matter}

Pre- and post- intervention responses concerning the continuous/particulate dimension of substances (Table 2, tasks 1-3) are presented in Table 3.

\section{[Insert Table 3 about here]}

Pre-intervention, although the majority of the teachers had some ideas about particles (PC and NEI), few had a complete particulate picture of substances for the solid, liquid and gas states (C). The critical factor here was the idea of empty space (vacuum) between the particles. Teachers in the PC category did not provide any clarification on this. For NEI, responses indicated continuous matter around the particles. A quarter of the teachers expressed no ideas about particles. Post intervention the distribution changes and the numbers of teachers who gave correct answers increase significantly for all physical states. The numbers of incorrect views have almost disappeared.

Given the differences in age and cognitive maturity a comparison between success rates for teachers and pupils would not be reasonable. However, compared to our pupil interventions there is an interesting difference in trends. In both pre and post tests, teachers' particle ideas varied from the solid to gas states in a different way to younger pupils. The teachers' resistance in accepting particle ideas is stronger for the solid state than the gas state; the difference is statistically significant $\left[\chi^{2}=226, \mathrm{p}<0.000\right]$. The opposite seems to hold true for pupils (Authors \#1 \& \#3, 2005; Author \#3, 1998a), who have more difficulty in accepting particle ideas for the gas state. The idea of 'nothing' between particles seems to be especially challenging for pupils. Macroscopically, pupils accept the solid and the liquid states, perhaps because they can see and feel them, but not the gas state, which is invisible. Thus, possibly it is easier for them to apply new ideas to something more familiar, like the solid state. With more macro-experiences the gas state may not be so mysterious for the teachers. Due to their education, teachers are likely to be more aware of the different properties of the three states, such as the compressibility of gas state. As a result they find it easier to conceive of a vacuum 


\section{Running head: Primary Teachers' Ideas of Physical Phenomena}

between the particles when the spaces are large. Gomez, Benarroch \& Marin (2006), report that the understanding of the high compressibility of gas state (compared to that of liquid state) increases with the conceptualization of the particulate nature of matter and is related to age (for ages 9 to 22 ).

For pupils aged 11 - 14 years old, Author \#3 (1998a) found that improvement in the Macroscopic/Collective dimension was more difficult than in the Continuous/Particulate dimension. Tasks 4 and 5 (Table 2) explored the macroscopic- collective dimension. First, teachers were asked to describe and compare particles of the same substance (water) in different states (task 4). For task 5 teachers were asked to go a little further and to do the same for different substances (sugar, water and oxygen) in different states (at room temperature). Here, the 'size' and 'shape' of particles, in addition to 'distance between particles' and 'motion' of particles, should be under consideration.

Table 4 shows the categories and frequencies of teachers' responses to the two tasks. Pre intervention, $40.7 \%$ were in category I for both $4 \mathrm{a}$ and $4 \mathrm{~b}$. These teachers clearly ascribed macroscopic characteristics to the particles; i.e. solid, liquid and gas particles for the three states, respectively. Post intervention, incorrect responses dropped to $7.4 \%$ of the teachers. From $7.3 \%$ pre-intervention, the percentage of teachers answering correctly (for both $4 \mathrm{a}$ and $4 \mathrm{~b})$ rose to $53.7 \%$.

For task 5, pre-intervention, $46.3 \%$ were in category I for both $5 \mathrm{a}$ and $5 \mathrm{~b}$. These teachers did not note differences in size and shape. Again, macroscopic properties were emphasised; i.e., solid particles for sugar, liquid particles for water and gas particles for oxygen. Post-intervention, a significant number, 19.8\%, remained in category I for both 5a and $5 \mathrm{~b}$. At $6.2 \%$ pre and $11.7 \%$ post intervention, the number in the correct category (for both $5 \mathrm{a}$ and $5 \mathrm{~b}$ ) was much lower than for task 4 . Comparing Tables 3 and 4, overall, the trend is similar to those we have found with pupils (Author \#3, 1998a; Author\#1 \& \#3, 2005). The macroscopic-collective dimension appears to be more difficult than the continuous-particulate 


\section{Running head: Primary Teachers' Ideas of Physical Phenomena}

dimension. Furthermore, appreciating that changes in motion and spacing alone (regardless of individual particle 'physical' nature) are sufficient to explain different states appears to be easier for a change of state than different substances in different states.

[Insert Table 4 about here]

\section{Part II: Describing and explaining phenomena}

Tables 5 and 6 present categories and frequencies of the teachers' responses to the four phenomena addressed in Part II of the test. There are two components for each phenomenon: the description of the event and the explanation.

\section{Melting}

Initially, most of the teachers described the liquid as still being wax (category C). Small numbers were either not definite in their answer (e.g. 'it is a liquid'- category PC) or referred to different names (e.g. it is water -category I). Neither of these necessarily implies that melted wax is being considered as a different substance. The former is a general description and the latter could be using 'water' as a 'prototype' for the liquid state. Indeed, the concept of a substance itself is not always clear for teachers (Author \#1 et al., 2000) and the non-conservation of substance identity seems to go against common sense (Author \#3, 2000, 2002). However, relatively few $(28-17.3 \%)$ gave acceptable particle structures for the solid and liquid states in their explanations. Post-instruction, all but one clearly identified the liquid as wax and $146(90.1 \%)$ gave a 'correct' particle explanation.

[Insert Table 5 about here]

\section{Boiling}

Pre intervention, similarly to pupils' answers in other studies (e.g. Authors \#1 \& \#3, 2005; Author \#3, 1998b; Hatzinikita \& Koulaidis, 1997; Osborne \& Cosgrove, 1983; Paik, 


\section{Running head: Primary Teachers' Ideas of Physical Phenomena}

Kim, Cho \& Park, 2004), most of the teachers gave 'alternative' ideas when asked about the content of the bubbles in boiling water. The most frequent response was 'air' (39\%, category NEI). Some caution in interpretation is needed here since 'air' could be a general term for the gas state (Author\#3 \& Other, 1996). For Greek people this might have additional reason to hold true since the words 'air' and 'gas' are alike in Greek language: air is 'aeras' and gas is 'aerio'. For category I, 26\% suggested either oxygen or hydrogen or both. Rather than some kind of separation, in some cases this could reflect a lack of distinction between the concepts of mixture (oxygen and hydrogen) and chemical compound (water, a compound of oxygen and hydrogen). Whatever some teachers might have meant, only $25 \%$ gave the 'simple' answer that the bubbles were water in the gas state (water vapour was accepted). Postintervention, the ideas concerning 'oxygen and /or hydrogen' were abandoned, but $15 \%$ persisted with 'air'. Most were in the correct category (68\%).

To explore the changes in structure between the liquid and gas states, the teachers were asked to give particle pictures for three areas: inside boiling water (liquid state), inside the bubbles (gas state) and just above the upper surface (where water is still in the gas state not where condensation would be seen). Pre-intervention, results show teachers having significant problems with the structure in each area. Misconceptions noted in Part 1 (Table 3) seemed to impact on their answers here (Table 5). Since most teachers assigned 'a gas' of some kind to the content of the bubbles (i.e., water vapor, air or some other gas - task 7a) it might be expected that the percentage giving a gas structure for inside a bubble would be high. However, only $50 \%$ of the teachers, pre- intervention, gave the correct structure for the bubble. Interestingly, $40 \%$ of these ( $20 \%$ of the total) did not give a correct gas state structure for the area just above the upper surface of the liquid. This indicates that these teachers had not understood a crucial part of the mechanism of the boiling: i.e., that the structure just above the upper surface is the same as the bubbles since this is where the content of the bubbles is released. Post-intervention the overall situation shows a statistically significant $(p<0.000)$ 


\section{Running head: Primary Teachers' Ideas of Physical Phenomena}

improvement. In relation to the gas state, $91.2 \%$ of the teachers gave the correct structure for the bubbles and only $7.4 \%$ of these could not give the correct structure for just above the upper surface as well.

\section{Evaporation}

The difference between boiling and evaporation at room temperature can be described at the macroscopic level and the particulate level. As the particulate level is examined in tasks $7 \mathrm{a}, \mathrm{b}$ and $8 \mathrm{~b}$, the categorization in $8 \mathrm{a}$ considered the macroscopic level. For a correct response to $8 \mathrm{a}$, answers were expected to address two criteria, explicitly or implicitly: i) that boiling takes place at a specific temperature whereas evaporation takes place over a range; ii) that the change takes place within the body of the liquid for boiling, whereas for evaporation it takes place at the surface. Pre-intervention, $43.2 \%$ of the teachers used both criteria for the distinction between boiling and evaporation satisfactorily (category C) and $29 \%$ addressed one (category PC). Nearly all of the teachers in the latter category referred to the temperature. Post-intervention, $91.4 \%$ fall in category $\mathrm{C}$.

Pre-intervention, very few teachers could use particle ideas to explain evaporation at room temperature (task 8 b). Only 6 cases $(0.3 \%)$ approached scientific thought (category C) using elements and terms from kinetic theory. These answers referred to a distribution of energy and the escape (individually) of high energy particles to mix in with the air particles. Those placed in category PC $(0.4 \%)$ implied this process, but without reference to energy distribution and the mixing with air particles. The majority $(81 \%)$ of teachers gave insufficient general descriptions (NEI). Many of these were tautologies (e.g. 'evaporation happens when a liquid evaporates', or 'evaporation happens when a liquid goes to the gas state'). Thus far, the teachers' formal science education (at least in Greece) seems to have been quite ineffective with regard to understanding this common phenomenon. Postintervention, increases to $33 \%$ for the category $\mathrm{C}$ and $43 \%$ for PC indicate a positive effect of 


\title{
Running head: Primary Teachers' Ideas of Physical Phenomena
}

the training course. However, it is quite clear that the challenge posed by evaporation at room temperature requires further attention.

\author{
[Insert Table 6 about here]
}

\section{Condensation}

In contrast to pupils (e.g. Authors \#1 \& \#3, 2005; Author \#3, 1998c; Bar \& Travis, 1991; Hatzinikita \& Koulaidis, 1997; Paik, Kim, Cho \& Park, 2004), the majority of the teachers seemed to appreciate that droplets appearing on a cold surface are water. Preintervention, $68 \%$ gave the correct answer, rising to $91 \%$ post-intervention. This could also be related to their richer everyday experiences compared to those of pupils. However, explanation is more problematic. Both, before and after the course, the large majority were in the PC category, $80 \%$ and $77 \%$ respectively. Here, responses acknowledged the role of the decreased temperature but went no further. Only one teacher pre-intervention and 22 post are in category $\mathrm{C}$. This required links between the temperature decrease, loss of particle energy and the grouping together of (water) particles to give droplets in the liquid state. In comparison to pupils (e.g. Authors \#1 \& \#3, 2005; Author \#3, 1998c; Paik, Kim, Cho \& Park, 2004), notwithstanding the teachers' greater comfort with the gas state (Part I) and their appreciation that the condensation is water, they also seem to have difficulty in explaining the phenomenon. As with evaporation at room temperature, condensation of atmospheric water seems to need further attention.

\section{Statistical Analysis}

The effect of the development of particle ideas

The relationships between particle model scores in Part I and description/explanation of phenomena scores in Part II were tested by correlation analysis. Treating the 


\section{Running head: Primary Teachers' Ideas of Physical Phenomena}

continuous/particulate and macroscopic/collective dimensions separately, Table 7 gives the calculated Spearman's rho correlation coefficients.

[Insert Table 7 about here]

Pre-intervention for the continuous/particulate dimension, correlation coefficients range from 0.16 to 0.58 and are all statistically significant. For the macroscopic/ collective dimension the correlations are generally lower and are not significant for melting and condensation. The latter lower correlations are not unexpected. Teachers holding weak particle models, which do not regard the particles as being the substance, would not necessarily think there would be any differences between individual particles for different states and substances. Their models have little explanatory power but they could still score on the measure of the macroscopic/collective dimension. About a third of the teachers had higher scores on the macroscopic/ collective dimension than the continuous/particulate dimension. Overall, the pre-intervention correlations give some indication of a relationship between the nature of a person's particle model and its contribution to understanding physical phenomena. Stronger indications have emerged in an analogous study with pupils, which used interviews to probe thinking (Author \#1 \& \#3, 2005). Post-intervention correlations are much lower but this is probably a function of the much larger numbers of high scores all round.

To further explore any relationship between the particle model dimensions and understanding physical phenomena, lowest and highest achievement groups of teachers for each dimension were selected for a two-way ANOVA. Each lowest-achievement group includes every case with achievement score lower than M-3SE, and each highest-achievement group includes every case with achievement score higher than M+3SE, where $\mathrm{M}$ is the mean achievement and SE is the standard error of score distribution. For the continuous/particulate dimension the lower and higher groups numbered 73 and 62 respectively. The parallel numbers for the macroscopic/collective dimension are 83 and 54. A two-way ANOVA was carried out using the total achievement score on physical phenomena as the dependent 


\section{Running head: Primary Teachers' Ideas of Physical Phenomena}

variable with Continuous/Particulate and Macroscopic/Collective as independent variables. Results are shown in Table 8 for the pre-intervention scores. Levene's test does not reject the equality of variances $(p=0.84)$, thus accuracy in the final statistical test is expected. The twoway ANOVA for pre-intervention test $[F(3,108)=30.4, p<0.000]$ explained $44.3 \%$ (Adj. R2 0.44) of the total variance: The main effect of the Particulate dimension is statistically significant and it explained $36.2 \%$ of the variance $[F(1,108)=61.1, p<0.000]$. The main effect of Collective dimension is statistically significant but very small - it explained $4.1 \%$ of the variance $[F(1,108)=4.57, p<0.035]$. Interaction effects of Particulate $\mathrm{x}$ Collective were not statistically significant.

\section{[Insert Table 8 about here]}

The above provides further support to the suggestion that understanding physical phenomena is related to understanding the particulate theory of substances. The relationship is only apparent in the pre-intervention measures, which reflect residual knowledge left from the teachers' formal education. This association is not too surprising. Those holding a weak particle model are not likely to find it useful for explanations. The key issue is the direction of any causality. Does particle theory open up the understanding of physical phenomena or vice versa? Our data do not provide any evidence either way. The large effect of the intervention obscures any relationship in the post-intervention scores.

\section{Which teachers benefited from the course?}

To give the overall picture, Figure 2 shows the distributions of the teachers' total scores for the pre and post tests. The effectiveness of the intervention per task is shown in Table 9. For each task the difference between pre-test/ post-test mean scores is statistically significant $(p<0.0001)$. In addition, the effect sizes (Type error II) estimated by using Pearson's r-vales (Field, 2001; Rosenthal, Rosnow \& Rubin, 2000) indicate that the 


\section{Running head: Primary Teachers' Ideas of Physical Phenomena}

magnitudes of these changes were substantial. Overall, the effect size on the total score is 0.89. Nonparametric tests, such as Wilcoxon Signed-Ranks test led to the same conclusions.

[Insert Figure 2 about here] and [Insert Table 9 about here]

The Spearman's rho correlation coefficient between pre-intervention and postintervention total test scores is 0.05 . Previous understanding is not a good predictor of success. Figure 3 depicts the changes between pre and post course performance in more detail. The different fill patterns labeled A, B, C, D and E represent the $15^{\text {th }}, 35^{\text {th }}, 50^{\text {th }}, 65^{\text {th }}$ and $85^{\text {th }}$ percentiles of the post course scores respectively. With the pre-intervention scores divided into five bands, the shading patterns indicate the achievements of the teachers in each pre-course score band. All percentile destinations on the post test are found for each score band on the pre-test.

[Insert Figure 3 about here]

\section{Effect of gender and teaching experience}

Table 10 compares the test means for males and females. For both pre and post intervention there are no significant gender differences. To test the effect of teaching experience, lowest and highest experience groups were selected. The lowest-experienced group (LExp) includes all cases with teaching experience lower than M-3SE, and the highestexperienced group (Hexp) includes all cases with teaching experience higher than $M+3 S E$, where $\mathrm{M}$ is the mean teaching experience and SE is the standard error.

[Insert Table 10 about here]

Comparing the test means for these two groups, table 10 shows a significant effect of teaching experience on the post-intervention test. Even though the lowest-experienced group (LExp) and highest experienced group (HExp) scored equivalently in the pre-intervention test, post-intervention, the HExp group scored significantly lower $(p<0.05)$. The most experienced/ oldest teachers showed less progress, that is, the resistance to conceptual change 


\section{Running head: Primary Teachers' Ideas of Physical Phenomena}

was greater. This may indicate that less experienced teachers' ideas are less consolidated and more easily changed (Sakonidis, Kaldrimidou \& Tzekaki, 2006) or reflect more general differences between attitude to change and age (Hewstone \& Stroebe, 2001). However, although statistically significant, the difference between the experience groups is small in comparison to the overall progress made by both groups.

\section{Conclusions}

The pre-intervention test showed that the primary teachers did not have a secure understanding of the physical phenomena and appeared to hold misconceptions similar to those that would be expected of their pupils. It seems reasonable to suppose that their thinking dates back to when they, themselves, were pupils. Furthermore, their experience of teaching these topics does not seem to have engendered any significant conceptual changes. There is nothing in the literature to suggest these teachers are atypical. A vicious cycle appears to be operating which allows misconceptions to persist from generation to generation. In an attempt to break this cycle, we have used a new conceptual approach to introducing the particle model in the context of physical changes. In this approach particle ideas are introduced within a substance-based framework rather than a 'solids, liquids and gases' framework. The focus is on explaining why a substance can be in any of the three states. Overall, the progress made by the teachers was encouraging. In comparison to in-service courses adopting constructivist teaching methodology within a 'solids, liquids and gases' approach we cannot say whether progress is better or worse. However, we would argue that our intervention has addressed important ideas, which teachers can take to and which offer the chance of breaking the cycle. The almost zero correlation between the pre and post scores is in keeping with the course providing a new conceptual approach. As might be expected, the more experienced teachers were found to be more resistant to change but the effect was not large. Many of the older teachers did make good progress. 


\section{Running head: Primary Teachers' Ideas of Physical Phenomena}

However, good progress is not complete progress. The teachers made the better progress with melting and boiling. For these changes of state, the taught model considered the particle energy collectively without reference to energy distribution. Melting was explained by the particles having enough energy to partially overcome the hold between particles. Boiling was explained by the particles having enough energy to completely overcome the hold. For a beaker of boiling water, the emphasis was on the water being in the gas state (the bubbles). The idea that enough water particles have enough energy (i.e. drawing on ideas of energy distribution) was not addressed. However, for evaporation below boiling point, ideas of energy distribution were introduced as a development of the particle model. This proved to be more difficult. Many teachers did not adopt ideas of energy distribution to explain room temperature evaporation. Similar difficulties have transpired in our work with primary pupils (Author\#3 \& \#1). However, a 'reduced' model where room temperature evaporation is explained by bombarding air particles 'knocking out' water particles (without reference to energy) had more appeal. The parallel, here, is with dissolving rather than a change of state. This does make a distinction from boiling and perhaps is sufficient for primary level. Identifying the condensation on a cold object as water was generally not a problem (pre and post). This implies appreciation that water exists within the air and this may be related to the teachers' willingness to accept the gas state. However, for most, the mechanism for condensation proved challenging. Understanding how water can exist as part of a gaseous mixture at room temperature and how this behaves on cooling is not easy. In addition to energy distribution, the idea of a balance between competing processes is also required: the chances of lower energy water particles meeting up versus the chances of clusters being broken up by higher energy particles (most likely air). After one intervention it is too early to judge whether such ideas are beyond most primary teachers and whether explaining the condensation of atmospheric water should be the preserve of specialist science teachers in secondary schools. The appropriateness for the primary curriculum is very doubtful. 


\section{Running head: Primary Teachers' Ideas of Physical Phenomena}

Notwithstanding issues surrounding mixtures of air and water, at the core of our approach is the use of the particle model to explain substances and their states. Our findings suggest this is accessible to primary pupils and their teachers. Like others (e.g. Jarvis, Pell \& Mckeon, 2003) we would recommend continuous in-service training programs where ideas could be revisited. Such programs should start as soon as teachers enter the classroom. There seems to be no advantage in waiting for teachers to gain some classroom experience. Furthermore, the present intervention course was focused on prerequisite content knowledge and attention should move on to enhancing pedagogical content knowledge (Boz \& Boz, 2008; Grossman, 1990; Park \& Oliver, 2008). A frequent reinforcement and development of the relevant ideas holds the potential for better teaching. Perhaps, in time, it might be possible to tip the vicious cycle into a virtuous cycle.

\section{References}

Andersson, B. (1986). Pupils' explanations of some aspects of chemical reactions. Science Education, 70(5), 549-563.

Andersson, B. (1990). Pupils' conceptions of matter and its transformations (age 12-16). Studies in Science Education, 18, 53-55.

Appleton, K. (1995). Student teachers' confidence to teach science: is more science knowledge necessary to improve self-confidence? International Journal of Science Education, 17(3), 357-369.

Appleton, K. (2002). Science activities that work: perceptions of primary school teachers. Research in Science Education, 32, 393-410.

Appleton, K. (2003). How do beginning primary school teachers cope with science? Toward an understanding of science teaching practice. Research in Science Education, 33, 1-25.

Author \#1 et al. (2000). Chemistry Education Research \& Practice.

Authors \#1, \& \#3 (2005). International Journal of Science Education. 
Running head: Primary Teachers' Ideas of Physical Phenomena

Author \#1, \#3 \& other (2008 ). Research in Science and Technological Education.

Author \#1 et al. (2007). Chemistry Education, Research \& Practice.

Author \#3 (1996). Education in Chemistry.

Author \#3 \& other (1996). Science Education.

Author \#3 (1998a). International Journal of Science Education.

Author \#3 (1998b). International Journal of Science Education.

Author \#3 (1998c). International Journal of Science Education.

Author \#3 (2000). International Journal of Science Education.

Author \#3 (2002). International Journal of Science Education.

Authors \#3 \& \#1 (2008). Submitted for publication. Draft available from Author\#3.

Baker, R. (1994). Teaching science in primary schools: what knowledge do teachers need? Research in Science Education, 24, 31-40.

Bar, V., \& Travis, A. S. (1991). Children's views concerning phase changes. Journal of Research in Science Teaching, 28(4), 363-382.

Bar, V., \& Galili, I. (1994). Stages of children's views about evaporation. International Journal of Science Education, 16(2), 157-174.

Barker, V. (2002). Beyond misconceptions: Students' misconceptions about basic chemical ideas, London, Royal Society of Chemistry.

Boz, N., \& Boz, Y, (2008). A Qualitative Case Study of Prospective Chemistry Teachers' Knowledge About Instructional Strategies: Introducing Particulate Theory. Journal of Science Teacher Education, 19, 135-156.

Ben-Zvi, R., Eylon, B. \& Silberstein, J. (1986). Is an atom of copper malleable? Journal of Chemical Education, 63(1), 64-66.

Çalık, M. (2008). Facilitating students' conceptual understanding of boiling using a four-step constructivist teaching method. Research in Science \& Technological Education, 26(1), $59-74$. 


\section{Running head: Primary Teachers' Ideas of Physical Phenomena}

Çalik, M., \& Ayas, A. (2005). A comparison of level of understanding of eighth-grade students and science student teachers related to selected chemistry concepts. Journal of research in science teaching, 42(6), 638-667.

Costou, B., \& Ayas, A. (2005). Evaporation in different liquids: secondary students' conceptions. Research in Science \& Technological Education, 23(1), 75-97.

Driver, R., Squires, A., Rushworth, P., \& Wood-Robinson, V. (1994). Making sense of secondary science research into children's ideas, Routledge.

Field, A. (2001). Meta-analysis of correlation coefficients: a Monte Carlo comparison of fixed and random effects methods. Psychological Methods, 6, 161-180.

Gabel, D., \& Bunce, D. (1994). Research on problem solving: Chemistry. In D.Gabel (Ed), Handbook of research on science teaching and learning (pp 301-326), New York, Macmillan.

Gabel, D., \& Sumuel K. (1987). Understanding the particulate nature of matter. Journal of Chemical Education, 64(8), 695-697.

Garnett, P.J., Garnett, P.J., \& Hackling, M.W. (1995). Students' Alternative Conceptions in Chemistry: A Review of Research and Implications for Teaching and Learning. Studies in Science Education, 25, 69-95.

Gomez, E. J., Benarroch, A., \& Marin, N. (2006). Evaluation of the degree of Coherence found in students' conceptions concerning the particulate nature of matter. Journal of research in science teaching, 43(6), 577-578.

Greek Pedagogical Institute (2003). National Program of Study for Primary and Secondary Education: Science. Athens (Greece): Greek Pedagogical Institute Publications.

Greek Ministry of National Education and Religion Affairs (1985). National Program of Study for Primary Education. Athens (Greece): Greek Publishing Association of textbooks. 


\section{Running head: Primary Teachers' Ideas of Physical Phenomena}

Griffiths, A., \& Preston, K. (1992). Grade-12 students' misconceptions relating to fundamental characteristics of atoms and molecules. Journal of Research in Science Teaching, 29(6), 611-628.

Grossman, P. L. (1990). The making of a teacher: Teacher knowledge and teacher education. New York: Teachers College Press.

Harlen, W., \& Holroyd, C. (1997). Primary teachers' understanding of concepts of science: impact on confidence and teaching. International Journal of Science Education, 19(1), 93105.

Harlen, W., Holroyd, C., \& Byrne, M. (1995). Confidence and understanding in teaching science and technology in primary schools. Scottish Council for Research in Science Education.

Harrison, A. G., \& Treagust, D.F. (2002). The particulate nature of matter: Challenges in understanding the submicroscopic world. In J. K. Gilbert, O. De Jong, R. Justi, D. Treagust \& J. H. Van Driel (Eds.), Chemical education: Towards research-based practice (pp 189-212). Dordrecht, Netherlands: Kluwer Academic Publishers.

Hatcher, L., \& Stepansky, E. J. (1994). A step-by-step approach to using the SAS system for univariate and multivariate statistics. Cary, NC: SAS Institute.

Hatzinikita, V., \& Koulaidis, V. (1997). Pupils' ideas on conservation during changes in the state of water. Research in Science \& Technology Education, 15 (1), 53-70.

Hatzinikita, V., Koulaidis, V., \& Hatzinikitas, A. (2005). Modeling pupils' understanding and explanations concerning changes in matter. Research in Science Education, 35, 471-495.

Hewstone, M., \& Stroebe, W. (Eds.) (2001). Introduction to Social Psychology (3 ${ }^{\text {rd }}$ ed.). U.K.: Blackwell Publishers.

Jarvis, T., Pell, A., \& Mckeon, F. (2003). Changes in primary teachers' science knowledge and understanding during a two year in-service programme. Research in Science \& Technological Education, 21(1), 17-42. 


\section{Running head: Primary Teachers' Ideas of Physical Phenomena}

Javis, T., \& Pell, A. (2004). Primary teaches' changing attitudes and cognition during a twoyear science in-service programme and their effect on pupils. International Journal of Science Education, 26(14), 1787-1811.

Jurievi, M., Glaar, S. A., Puko, C.R., \& Devetak, I. (2008). Intrinsic Motivation of Pre-service Primary School Teachers for Learning Chemistry in Relation to their Academic Achievement. International Journal of Science Education, 30(1), 87-107.

Kang, N. H. (2007). Elementary Teachers' Epistemological and Ontological Understanding of Teaching for Conceptual Learning. Journal of Research in Science Teaching, 44(9), 12921317.

Kokkotas, P., Vlachos, I., \& Koulaidis, V. (1998). Teaching the topic of the particulate nature of matter in prospective teachers' training courses. International Journal of Science Education, 20(3), 291- 303.

Kline, P. (1999). The handbook of psychological testing (2nd edition). London: Routledge.

Krnel, D., Watson, R., \& Glazar, S.A. (1998). Survey of research related to the development of the concept of matter. International journal of science education, 20(3), 257-289

Krugar, C., Summers, M. \& Palacio, D. (1990) A survey of primary school teachers' conceptions of force and motion. Educational Research, 32(2), 83-95.

Lee, O., Eichinger, D., Anderson, C., Berkheimer, C., \& Blakeslee, T. (1993). Changing middle school students' conceptions of matter and molecules. Journal of Research in Science Teaching, 30(3), 249-270.

Liang, L., \& Gabel, D. (2005). Effectiveness of a constructivist approach to Science instruction for prospective elementary teachers. International journal of science education, 27(10), 1143-1162.

Liu, X. (2001). Synthesizing research on conceptions in science. International Journal of Science Education, 23(1), 55-81. 


\section{Running head: Primary Teachers' Ideas of Physical Phenomena}

Mant, J., \& Summers, M. (1995). Some primary school teachers' understanding of the Earth's place in the universe. Research Papers in Education, 8(1), 101-129.

Martin, O., Mullis, I., Gonzales, E., \& Chrostowski, S. (2004). Timss 2003 international science report. International Association for the Evaluation of Educational Achievement (IEA), Boston College, MA: TIMSS and PIRLS International Study Centre.

Mertens, D. (2005). Research and Evaluation in Education and Psychology. London: Sage Publications.

Morrison, J.A., \& Lederman, N.G. (2003). Science teachers' diagnosis and understanding of students' preconceptions. Science Education, 87, 849-867.

Murphy, C., Neil, P., \& Beggs, J. (2007). Primary science teacher confidence revisited: ten years on. Educational Research, 49(4), 415-30.

Osborne, R. J., \& Cosgrove, M. M. (1983). Children's conceptions of the changes of state of water. Journal of Research in Science Teaching, 20(9), 825-838.

Osborne, J., \& Simon, S. (1996). Primary science: past and future directions. Studies in Science Education, 26, 99-147.

Paik, S.-H., Kim, H.-N., Cho, B.-K., \& Park, J.-W. (2004). K-8 ${ }^{\text {th }}$ grade Korean students' conceptions of 'changes of state' and conditions for changes of state'. International Journal of Science Education, 26(2), 207-224.

Park, S., \& Oliver, J. S. (2008). Revisiting the Conceptualisation of Pedagogical Content Knowledge (PCK): PCK as a Conceptual Tool to Understand Teachers as Professionals. Research in Science Education, 38, 261-284.

Parker, J., \& Heywood, D. (2000). Exploring the relationship between subject knowledge and pedagogical content knowledge in primary teachers' learning about forces. International Journal of Science Education, 22(1), 89-111.

Pereira, M. P. \& Pestana, E.M. (1991). Pupils' representations of models of water. International Journal of Science Education, 13(3), 313-319. 


\section{Running head: Primary Teachers' Ideas of Physical Phenomena}

Rosenthal, R., Rosnow, R. L., \& Rubin, D. B. (2000). Contrasts and effect sizes in behavioural research: a correlational approach. Cambridge, Cambridge University Press.

Russell, T., Harlen, W., \& Watt, D. (1989). Children's ideas about evaporation. International Journal of Science Education, 11 (special issue), 566-576.

Sakonidis, H., Kaldrimidou, M., \& Tzekaki, M. (2006). Experts' and novices' primary teachers' intervening in students' mathematical activity: an insight. In J. Novotna, H. Moraova, M. Kratka \& N. Stehlikova (Eds), Proceedings of the $30^{\text {th }}$ International Conference for the Psychology of Mathematics Education, Charles University of Prague, Czech Republic.

Schibeci, R.A., \& Hickey, R. (2000). Is it natural or processed? Elementary school teachers' and conceptions about materials. Journal of Research in Science Teaching, 37(10), 11541170.

Schoon, K. J., \& Boone, W. J. (1998). Self-efficacy and alternative conceptions of science of preservice elementary teachers. Science Education, 82, 553-568.

Smith, C., Anderson, C., Krajcik, J., \& Coppola, B. (2004). Implications of research on children's learning for assessment: Matter and atomic molecular theory, Paper commissioned by the Committee on Test Design for K-12 Science Achievement, Center for Education, National Research Council.

Smith, D.C., \& Neal, D.C. (1989). The construction of subject matter knowledge in primary science teaching. Teaching \& Teacher Education, 5, 1-20.

Stavy, R. (1990). Children's conception of changes in the state of matter from liquid (or solid) to gas. Journal of Research in Science Teaching, 27(3), 247-266.

Summers, M. (1992). Improving primary school teachers' understanding of science concepts - theory into practice. International Journal of Science Education, 14(1), 25-40.

Summers, M., \& Krugar, C. (1992). Research into English primary teachers' understanding of the concept of energy. Evaluation and Research in Education, 6, 95-111. 
Running head: Primary Teachers' Ideas of Physical Phenomena

Tekkaya, C., Cakiroglu, J., \& Ozkan, O. (2004). Turkish preservice science teachers' understanding of science and their confidence in teaching it. Journal of Education for Teaching, 30(1), 57-68.

Tytler, R. (2000). A comparison of year 1 and year 6 students; conceptions of evaporation and condensation: Dimensions of conceptual progression. International Journal of Science Education, 22(5), 447-467.

Woolnough, B.(1994). Effective science teaching, Buckingham, Open University Press. 


\section{Running head: Primary Teachers' Ideas of Physical Phenomena}

Table 1. Outline of content of the teaching scheme concerning physical changes.

\section{Properties and the material/object distinction}

Some properties depend on the material only.

Some properties depend on the material, the amount (dimensions of an object) and the shape/structure of an object.

\section{Definition of a substance.}

Melting behaviour can be used to distinguish between a pure sample of a substance and a mixture of substances.

\section{A simple particle model}

Particle ideas can explain melting.

A sample of a substance was presented as a collection of particles with empty space between.

Key points were:

- The particles have an ability to 'hold on' to each other:

- They are always moving in some way (energy of movement): and

- The particles of a particular substance remain the same in a change of state.

\section{A sample of a substance could be in one of three states.}

A sample of a substance can be in the gas state.

Explanations for the phenomena of melting and boiling

Why different substances can be in different states at room temperature.

\section{Mixing and unmixing.}

Distribution of energy among the particles of a substance.

Evaporation below boiling point into the air.

Condensation of atmospheric water vapour. 


\section{Running head: Primary Teachers' Ideas of Physical Phenomena}

Table 2. Description of the instrument. Parts and tasks.

\begin{tabular}{|c|c|c|c|c|}
\hline Parts & Descri & ption of Parts & Tasks & Description of Tasks \\
\hline \multirow[t]{5}{*}{$\mathbf{I}$} & $\begin{array}{l}\text { Particulate- } \\
\text { Continuous }\end{array}$ & Solid state & 1 & $\begin{array}{l}\text { Description of what can be seen inside a grain of sugar, } \\
\text { if it could be magnified a huge amount. }{ }^{1}\end{array}$ \\
\hline & & Liquid state & 2 & $\begin{array}{l}\text { Description of what can be seen inside a drop of water, if } \\
\text { it could be magnified a huge amount. }{ }^{1}\end{array}$ \\
\hline & & Gas state & 3 & $\begin{array}{c}\text { Description of what can be seen inside a spotted area of } \\
\text { oxygen (in gas state in a vase), if it could be magnified a } \\
\text { huge amount. }{ }^{1}\end{array}$ \\
\hline & $\begin{array}{l}\text { Macroscopic- } \\
\text { Collective }\end{array}$ & $\begin{array}{l}\text { Same } \\
\text { Substance in different } \\
\text { states }\end{array}$ & 4 & $\begin{array}{l}\text { Description and comparison between single particles of } \\
\text { water in the three states. }\end{array}$ \\
\hline & & $\begin{array}{l}\text { Different } \\
\text { substances in different } \\
\text { states at room temp. }\end{array}$ & 5 & $\begin{array}{l}\text { Description and comparison between single particles of } \\
\text { sugar, water and a gas in room temperature. }{ }^{2}\end{array}$ \\
\hline \multirow[t]{4}{*}{ II } & $\begin{array}{c}\text { Physical } \\
\text { Phenomena }\end{array}$ & Melting & 6 & $\begin{array}{l}\text { Description and comparison between the two states of } \\
\text { wax during melting, i.e., before and after melting. }{ }^{3}\end{array}$ \\
\hline & & Boiling & 7 & $\begin{array}{c}\text { Description and comparison among three areas of } \\
\text { boiling water, i.e., the liquid area, inside a bubble and } \\
\text { upper the surface of boiling water. }\end{array}$ \\
\hline & & Evaporation & 8 & Description /explanation of evaporation of water..$^{5}$ \\
\hline & & Condensation & 9 & $\begin{array}{l}\text { Description /explanation of condensation of water on a } \\
\text { cool surface. }{ }^{6}\end{array}$ \\
\hline
\end{tabular}

1. Teachers were asked to draw a relevant picture and to explain what they draw: There were some pictures given in order to stimulate their imagination (Figure 1). Teachers could pick up one of these pictures or draw their own, in case none of these satisfied them. In any case teachers should explain what the picture presents indicating and naming any part of the picture.

2. Teachers were asked to answer this question only if there were a reference to particles in their previous answers. Otherwise, they encouraged to proceed to part II.

3. A macroscopic description of a piece of wax melting is given as stimulus. Teachers were asked to name the material after melting and to describe the structure of wax before and after melting drawing corresponding microscopic picture (teachers could also use pictures of Figure 1).

4. A macroscopic picture of boiling water inside a beaker is given as stimulus. Teachers were asked to name the material in the liquid area, inside a bubble and right upper the surface of boiling water and to describe the structure of these three areas drawing corresponding microscopic pictures (teachers could also use pictures of Figure 1).

5. A macroscopic description of evaporation (below boiling point) of water is given as stimulus. Teachers were asked to describe and explain the phenomenon of evaporation (of water), as well as, to make a distinction between boiling and evaporation.

6. A macroscopic description of the formation of drops on a cool surface of a can is given as stimulus. Teachers were asked to name the material of drops and give explanations for their formation. 
Running head: Primary Teachers' Ideas of Physical Phenomena

Table 3. Categories of teachers' responses $(n=162)$ in Continuous/Particulate dimension. Preand post-intervention frequencies* for substances in the three states of matter at room temperature.

\begin{tabular}{cccccccc}
\hline Category & Score & \multicolumn{2}{c}{ Solid } & \multicolumn{2}{c}{ Liquid } & \multicolumn{2}{c}{ Gas } \\
\hline & & Pre & Post & Pre & Post & Pre & Post \\
\cline { 2 - 8 } I & 0 & 48 & 6 & 37 & 0 & 40 & 1 \\
NEI & 1 & 82 & 24 & 67 & 9 & 21 & 14 \\
PC & 2 & 25 & 75 & 43 & 77 & 74 & 64 \\
C & 3 & 7 & 67 & 15 & 76 & 27 & 83 \\
\hline
\end{tabular}

$\mathrm{C}($ correct $)=$ complete picture of microscopic structure.

PC $($ partially correct $)=$ notion of particles but not clearly address the nature of the free space.

NEI (not entirely incorrect) $=$ particles in continuous matter.

$\mathrm{I}($ incorrect $)=$ continuous matter, irrelevant or no answer

* Pre - post comparisons: Solid $=\left[\chi^{2}=692, p<0.0000\right]$, Liquid $=\left[\chi^{2}=325, p<0.0000\right]$, Gas $=\left[\chi^{2}=119, p<0.0000\right]$. 
Running head: Primary Teachers' Ideas of Physical Phenomena

Table 4. Categories of teachers' responses in Macroscopic-Collective dimension. Pre- and post-intervention frequencies* $(n=162)$.

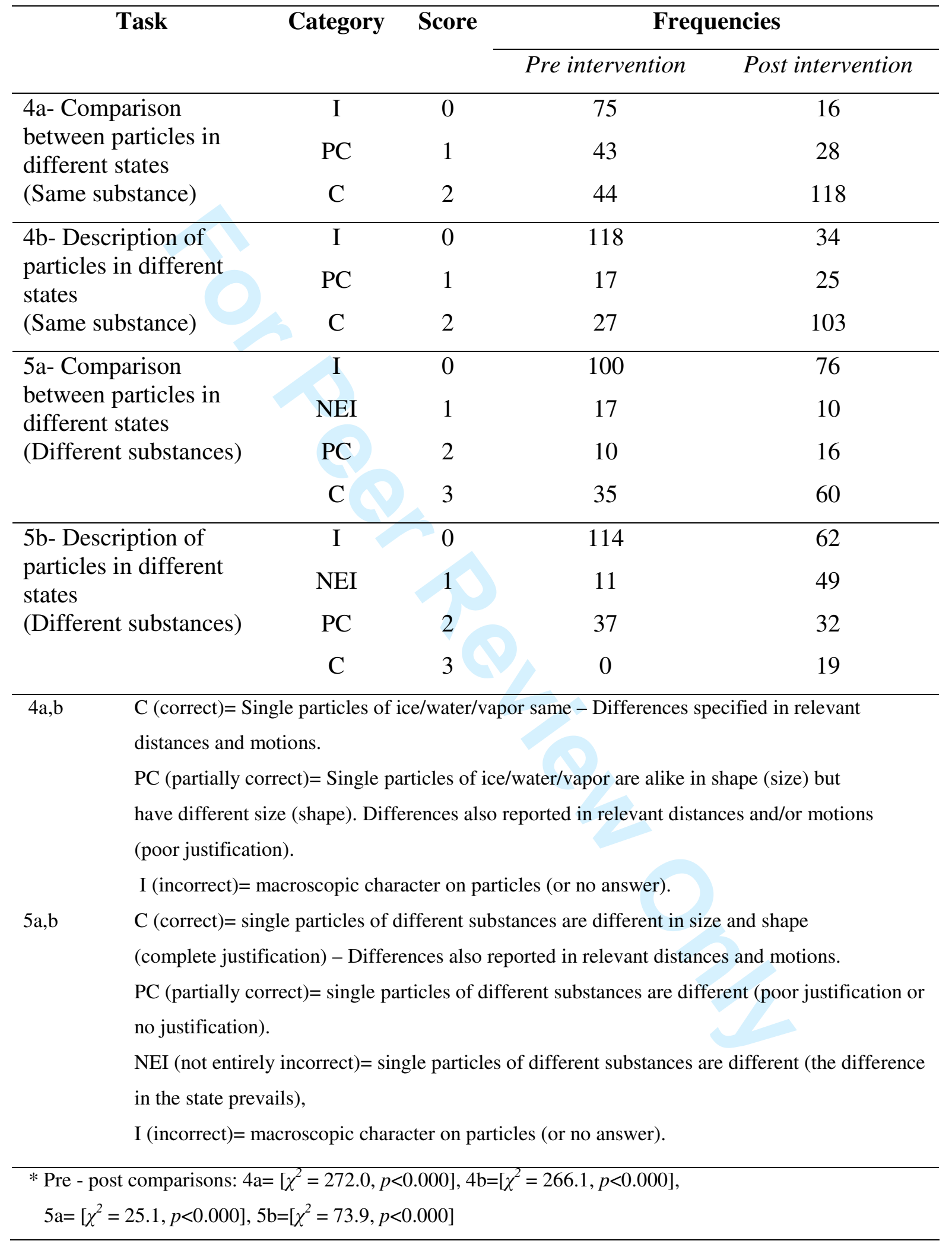


Running head: Primary Teachers' Ideas of Physical Phenomena

Table 5. Categories of teachers' descriptions concerning melting wax and boiling of water $(\mathrm{n}=162)$. Pre- and post-intervention frequencies.

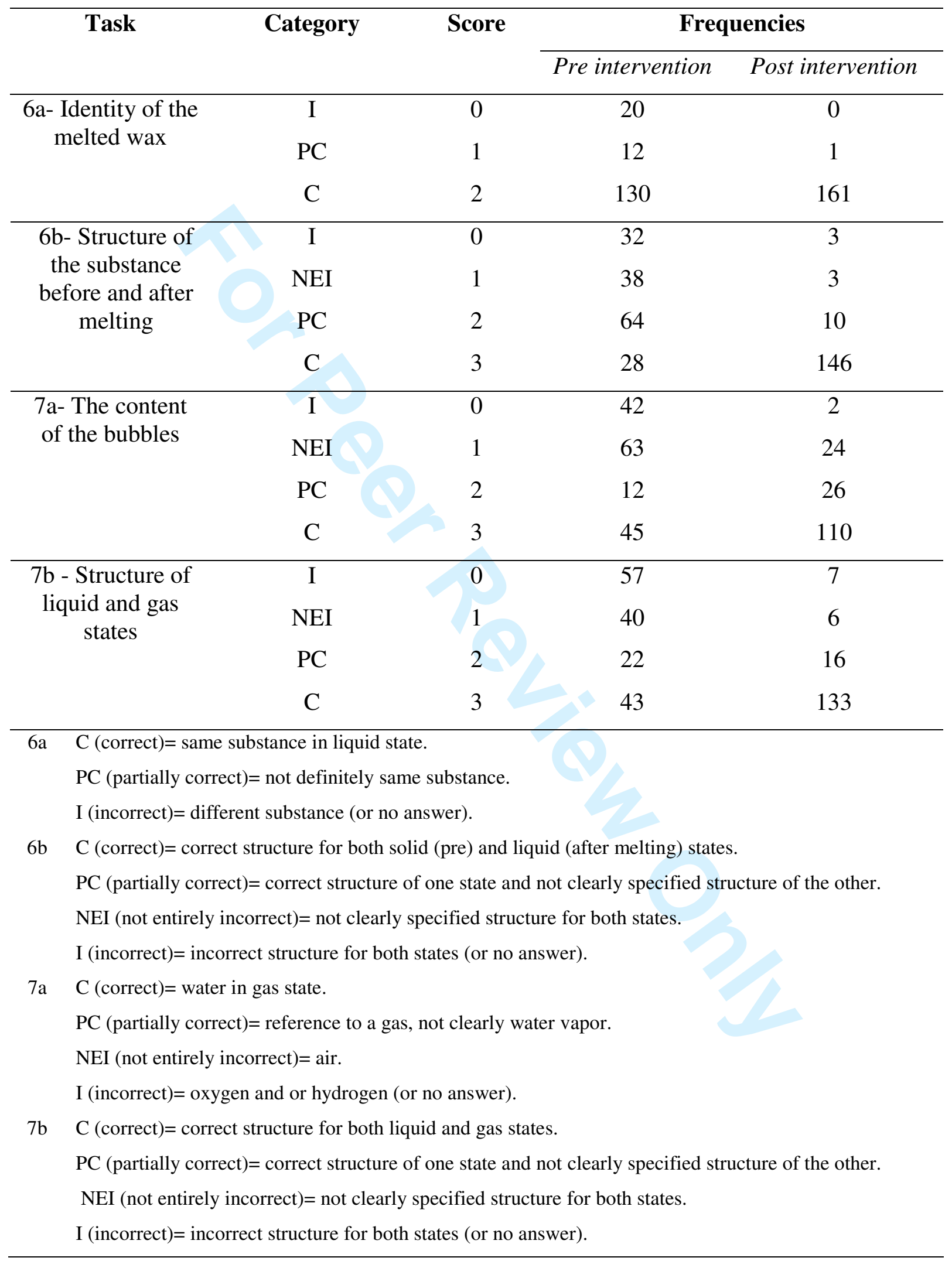


Running head: Primary Teachers' Ideas of Physical Phenomena

Table 6. Categories of teachers' descriptions of evaporation and condensation $(n=162)$. Preand post-intervention frequencies.

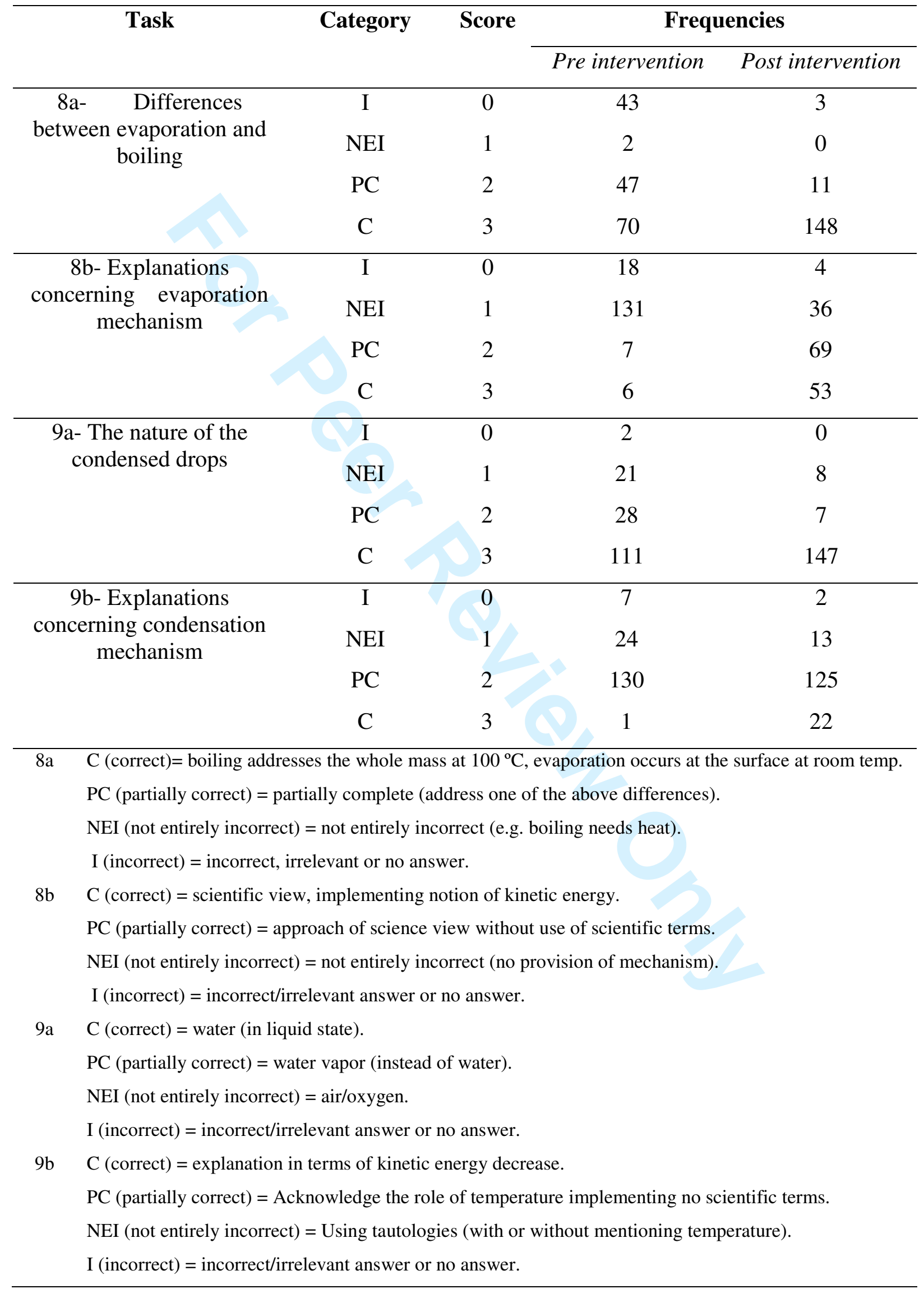


Running head: Primary Teachers' Ideas of Physical Phenomena

Table 7. Correlation analysis $(n=162)$ of the Continuous/Particulate and the Macroscopic/ Collective dimension with the achievement in explaining physical phenomena.

\begin{tabular}{llllllc}
\hline $\begin{array}{l}\text { Spearman's rho Dimension } \\
\text { Correlations }\end{array}$ & Melting & Boiling & Evaporation Condensation & Total \\
\hline Pre Intervention & Particulate & $0.44^{* *}$ & $0.46^{* *}$ & $0.26^{* *}$ & $0.16^{*}$ & $0.58^{* *}$ \\
& Collective & 0.07 & $0.28^{* *}$ & $0.29^{* *}$ & 0.05 & $0.32^{* *}$ \\
\hline Post Intervention & Particulate & $0.20^{*}$ & -0.11 & $0.20^{*}$ & $0.19^{*}$ & 0.14 \\
& Collective & 0.14 & 0.11 & 0.15 & $0.16^{*}$ & $0.24^{* *}$ \\
\hline$* * p<0.01 ; * p<0.05$ & & & & &
\end{tabular}

Table 8. Two-way ANOVA: (Pre intervention).

\begin{tabular}{lccccc}
\hline \multicolumn{5}{c}{ Tests of Between-Subjects Effects: Dependent Variable: Pre-intervention scores } \\
\hline \multicolumn{1}{c}{ Source } & Type III Sum of & & & & \\
& Squares & df & Mean Square & $\boldsymbol{F}$ & $\boldsymbol{p}$ \\
\hline Corrected Model & 614.6623 & 3 & 204.8874 & 30.37 & 0.000 \\
Intercept & 20881.07 & 1 & 20881.07 & 30.95 & 0.000 \\
Particulate & 412.2559 & 1 & 412.2559 & 61.12 & 0.000 \\
Collective & 30.84193 & 1 & 30.84193 & 4.57 & 0.035 \\
Particulate x Collective & 8.418619 & 1 & 8.418619 & 1.25 & 0.266 \\
Error & 728.4449 & 108 & 6.74486 & & \\
Total & 24372 & 112 & & & \\
Corrected Total & 1343.107 & 111 & & & \\
\hline R Squar & & & & & \\
\hline
\end{tabular}

R Squared $=0.458$ (Adjusted R Squared $=0.443$ ) 
Running head: Primary Teachers' Ideas of Physical Phenomena

Table 9. Teachers' mean scores and standard deviations expressed as percent achievement in all tasks. T-test between pre-intervention and post-intervention scores and the effect size.

\begin{tabular}{ccccccc} 
& \multicolumn{2}{c}{ Pre Intervention } & \multicolumn{2}{c}{ Post Intervention } & T-test & Effect size \\
\cline { 2 - 7 } & Mean & SD & Mean & SD & $\boldsymbol{t}$ & $\boldsymbol{r}$ \\
\hline Particulate & 35.7 & 21.6 & 73.6 & 19.6 & $-15.4^{*}$ & 0.77 \\
Collective & 26.5 & 24.1 & 54.8 & 25.4 & $-12.2^{*}$ & 0.69 \\
Melting & 64.4 & 25.0 & 96.8 & 10.7 & $-15.6^{*}$ & 0.78 \\
Boiling & 44.8 & 28.7 & 86.7 & 21.1 & $-16.4^{*}$ & 0.79 \\
Evaporation & 53.5 & 20.6 & 85.9 & 13.2 & $-18.7^{*}$ & 0.83 \\
Condensation & 71.7 & 15.8 & 81.5 & 13.4 & $-6.0^{*}$ & 0.42 \\
Total & 44.5 & 14.2 & 76.5 & 10.1 & $-24.1^{*}$ & 0.89 \\
\hline$* p<0.0001$ & & & & & &
\end{tabular}

Table 10. The effects of teaching experiences and gender on the $\%$ total achievement score.

\begin{tabular}{|c|c|c|c|c|c|c|c|}
\hline \multirow[b]{2}{*}{ Total score } & & \multirow[b]{2}{*}{$\mathbf{N}$} & \multirow[b]{2}{*}{ Mean } & \multirow[b]{2}{*}{ SD* } & \multicolumn{2}{|c|}{ T-test } & \multirow{2}{*}{$\begin{array}{c}\text { Effect size } \\
\boldsymbol{r}\end{array}$} \\
\hline & & & & & $t$ & $p$ & \\
\hline \multirow[t]{2}{*}{ Pre intervention } & Male/ Female & $68 / 94$ & $46.6 / 42.8$ & $14.3 / 14.2$ & 1.66 & 0.098 & 0.13 \\
\hline & Lexp/ Hexp & $52 / 42$ & $40.9 / 46.6$ & $13.6 / 13.6$ & -1.97 & 0.052 & 0.20 \\
\hline \multirow[t]{2}{*}{ Post intervention } & Male/ Female & $68 / 94$ & $76.2 / 76.6$ & $10.6 / 9.8$ & -0.23 & 0.821 & 0.02 \\
\hline & Lexp/ Hexp & 5242 & $78.5 / 73.0$ & $9.8 / 11.1$ & 2.46 & 0.016 & 0.26 \\
\hline
\end{tabular}

\footnotetext{
* In all cases, Levene's test does not reject the equality of variances.
} 
1

2

3

4

5

6

7

8

9

10

11

12

13

14

15

16

17

18

19

20

21

22

23

24

25

26

27

28

29

30

31

32

33

34

35

36

37

38

39

40

41

42

43

44

45

46

47

48

49

50

51

52

53

54

55

56

57

58

59

60
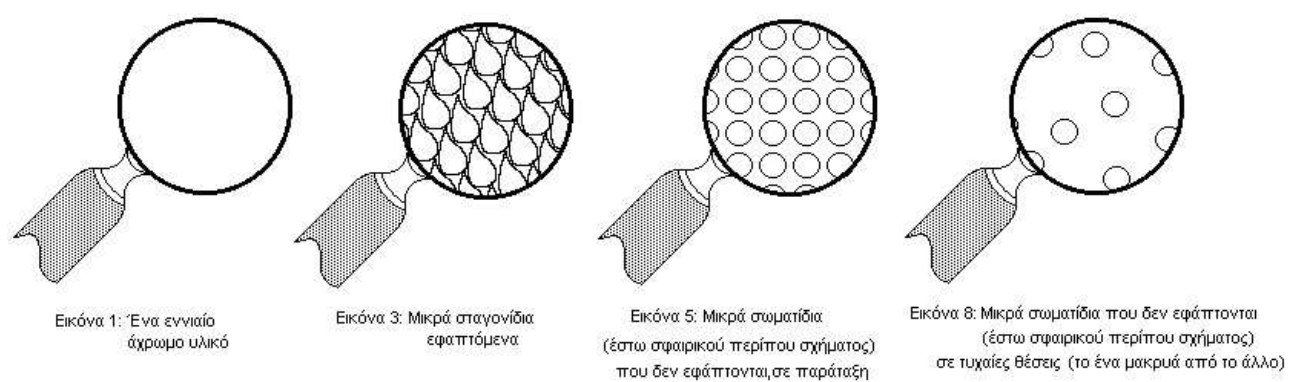

Figure 1: Some of the pictures, which were included in the test as a stimulus. Clarifications on what the picture presents, are also given below the pictures. [Picture 1: A continuous colourless material, Picture 3: Small droplets, the one touch on the other, Picture 5: particles (like small spheres, the one does not touch on the other, in certain positions), Picture 8: particles (like small spheres, the one away from the other, in random positions)]

$224 \times 69 \mathrm{~mm}(96 \times 96 \mathrm{DPI})$ 


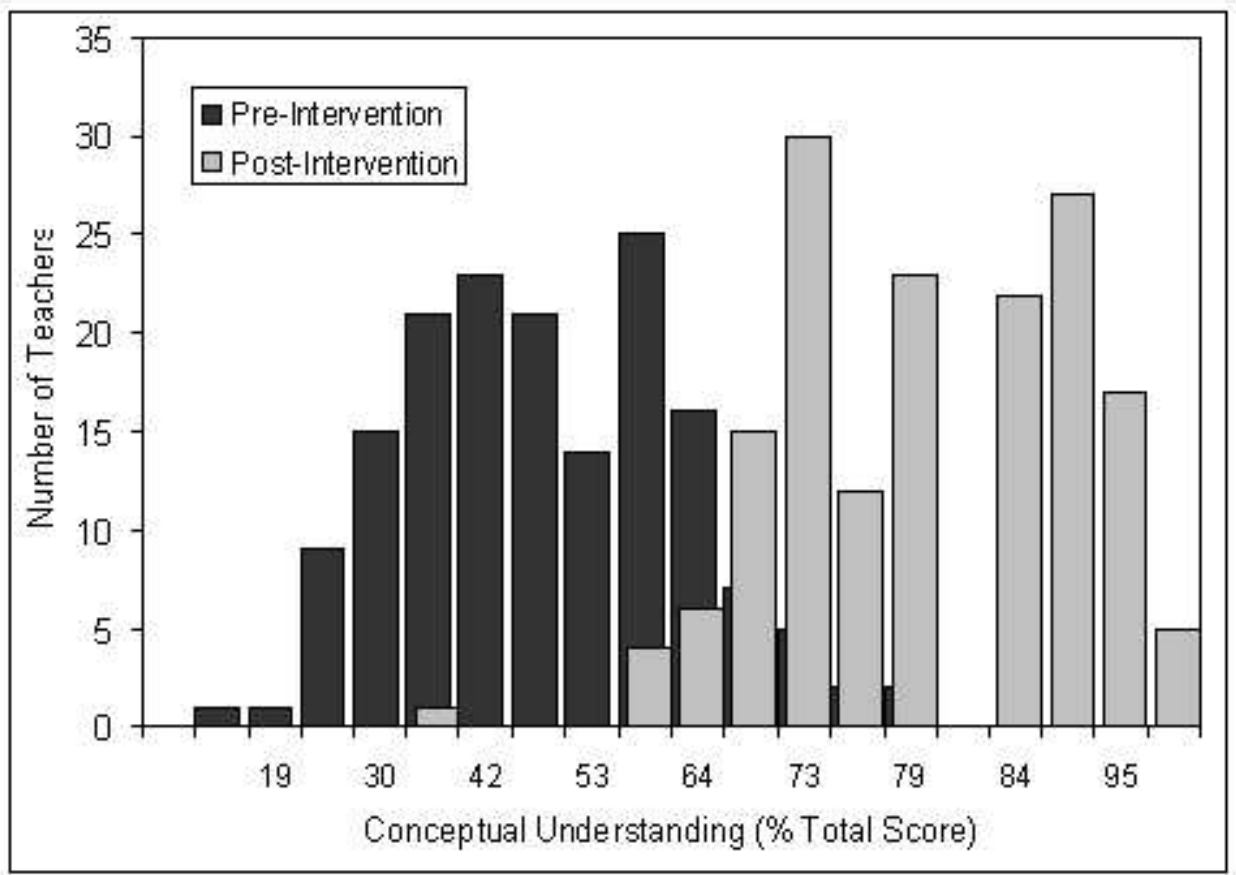

Figure 2: Distribution of total score for pre-intervention and post-intervention tests. $127 \times 90 \mathrm{~mm}(96 \times 96 \mathrm{DPI})$ 


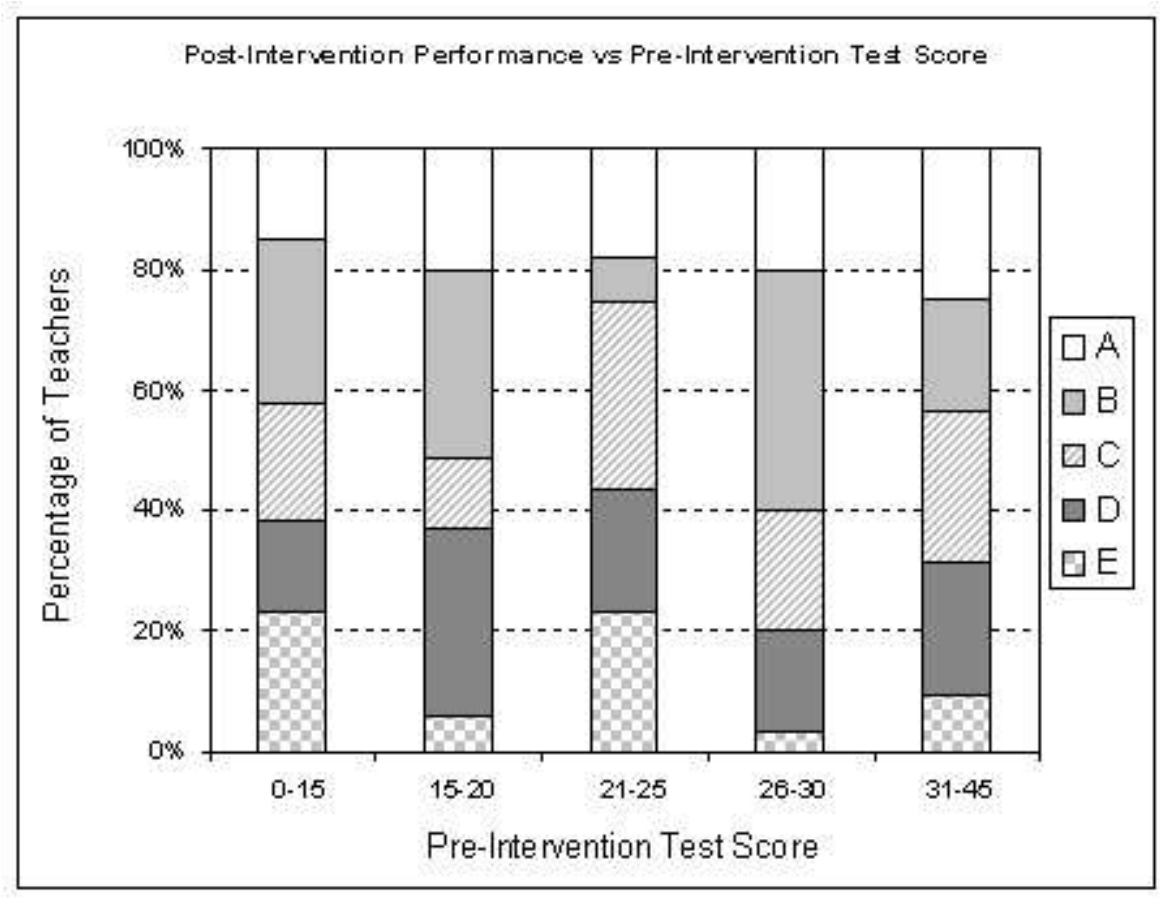

Figure 3: Post-intervention performance versus pre-intervention tests scores. $119 \times 91 \mathrm{~mm}(96 \times 96 \mathrm{DPI})$ 